\title{
Synthesis, Structural and Magnetic Properties of Copper Substituted Nickel Ferrites by Sol-Gel Method
}

\author{
Gopathi Ravi Kumar ${ }^{1 *}$, Katrapally Vijaya Kumar ${ }^{2}$, Yarram Chetty Venudhar ${ }^{1}$ \\ ${ }^{1}$ Department of Physics, Osmania University, Hyderabad, India; ${ }^{2}$ Department of Physics, JNTU Hyderabad College of Engineering, \\ Nachupally (Kondagattu), India. \\ Email: "gravikumarou@gmail.com
}

Received September 22 $2^{\text {nd }}, 2011$; revised November $23^{\text {rd }}, 2011$; accepted December $21^{\text {st }}, 2011$

\begin{abstract}
The $\mathrm{Ni}_{1-x} \mathrm{Cu}_{x} \mathrm{Fe}_{2} \mathrm{O}_{4}(x=0.0,0.1,0.2,0.3,0.4,0.5,0.6,0.7,0.8,0.9,1.0)$ ferrites have been prepared by sol-gel method in order to obtain homogeneous crystal structure and they are sintered at high temperature. The effect of copper doping on the structural and magnetic properties of nickel ferrites sintered at $1000^{\circ} \mathrm{C}$ has been examined. The X-ray diffraction measurements clearly showed the formation of single phase spinel ferrite structure in all the prepared ferrite compositions. Because of the high sintering temperature the particle size is observed beyond the nano-scale range in all the compositions. The lattice parameters are found to increase with increasing doping concentration of the copper content. Magnetization results exhibit a non-collinear ferrimagnetic structure for $x=0.0$ to 0.5 and Neel's collinear ferrimagnetic structure for $x=0.5$ to 0.9 suggesting a change in magnetic ordering.
\end{abstract}

Keywords: Ferrite; High Sintering Temperature; X-Ray Diffractograms; Spinel Structure; SEM; Magnetic Properties

\section{Introduction}

Ferrites are technologically essential materials that are used in the fabrication of magnetic, electronic and microwave devices. They have gained technological importance by virtue of their high resistivity and negligible eddy current losses [1,2]. Nickel and copper substituted nickel ferrites are the important class of spinel ferrites [3]. According to crystal structure, nickel ferrite is an inverse spinel ferrite and possesses high electrical resistivity and low eddy current losses. The substitution of copper in nickel ferrite modifies the properties of nickel ferrite which are useful in many device applications. Nickel-copper ferrites play significant role among magnetic materials due to their high electrical resistivity, high saturation magnetization and high magnetic permeability [4,5]. The structural and magnetic properties of spinel ferrites depend on the magnetic interaction and cation distribution in the two sub-lattices i.e. tetrahedral (A) and octahedral (B) lattice sites. $\mathrm{Ni}-\mathrm{Cu}$ ferrites have appealing electrical and magnetic properties, as copper ferrite is one of the most interesting spinel ferrite among all the ferrites. It undergoes a structural phase transition accompanied by a reduction in the crystal symmetry to tetragonal [6].

It has been reported by several research groups that, the magnetization in $\mathrm{Ni}-\mathrm{Cu}$ ferrites decreases with increasing $\mathrm{Cu}$ content and vice-versa [7-14]. The $\mathrm{Cu}$ con-

"Corresponding author. tent was found to have a significant influence on the electromagnetic properties. Therefore it would be meaningful to investigate the structural and magnetic properties of Ni-Cu ferrites. Thus, in this paper, we present the systematic investigations of $\mathrm{Cu}$ substituted nickel ferrites.

\section{Experimental Procedure}

$\mathrm{Ni}-\mathrm{Cu}$ ferrites with a generic formula $\mathrm{Ni}_{1-x} \mathrm{Cu}_{x} \mathrm{Fe}_{2} \mathrm{O}_{4}(0.0 \leq x$ $\leq 1.0$ ) were synthesized by sol-gel method [15]. All of the chemicals were analytical grade with purity $\geq 99 \%$ and were used. In a typical procedure, the nickel nitrate hydrate $\mathrm{Ni}$ $\left(\mathrm{NO}_{3}\right)_{2} \cdot 6 \mathrm{H}_{2} \mathrm{O}$, cupric nitrate hydrate $\mathrm{Cu}\left(\mathrm{NO}_{3}\right)_{2} \cdot 6 \mathrm{H}_{2} \mathrm{O}$, ferric nitrate nonahydrate $\mathrm{Fe}\left(\mathrm{NO}_{3}\right)_{3} \cdot 9 \mathrm{H}_{2} \mathrm{O}$ were used as starting materials. The synthesis process is described elsewhere [15]. The final powder samples obtained were sintered at $1000^{\circ} \mathrm{C}$ for $24 \mathrm{~h}$.

Structural characterization of the ferrite powders was carried out on Panalytical Expert Diffractometer (XRD), PW 3040/60 Philips with $\mathrm{CuK} \alpha$ radiation (wavelength, $\lambda$ $=1.54 \AA$ ). The scanning electron micrographs of all the samples were taken on JEOL JSM 6360 SEM machine. Magnetization measurements were performed using the vibrating sample magnetometer (VSM).

\section{Results and Discussions}

Figure 1 shows the XRD patterns of $\mathrm{Ni}_{1-x} \mathrm{Cu}_{x} \mathrm{Fe}_{2} \mathrm{O}_{4}(0 \leq$ 


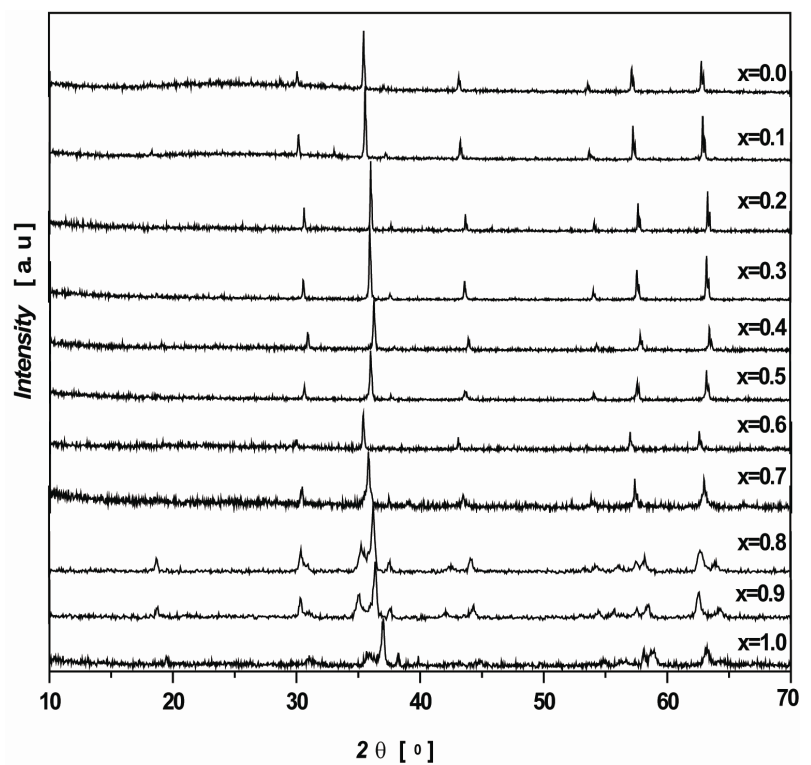

Figure 1. X-ray diffractograms of $\mathrm{Ni}_{1-x} \mathrm{Cu}_{x} \mathrm{Fe}_{2} \mathrm{O}_{4}(0 \leq x \leq 1.0)$ ferrites.

$x \leq 1.0)$ samples. The X-ray diffractograms clearly indicate the formation of single phase spinel structure. The XRD patterns were compared and indexed using ICDD card no (86-2287) and (34-0425) for $\mathrm{Ni}$ and $\mathrm{Cu}$ ferrites. As seen from Figure 1, the XRD peaks are very narrow indicating the higher grain size falls beyond the nanoscale region (more than $100 \mathrm{~nm}$ ). Generally the sol-gel technique yields nano size grains in the ferrite systems [15]. But, as the sintering temperature and sintering time $\left(1000^{\circ} \mathrm{C}\right.$ for $\left.24 \mathrm{~h}\right)$ were very high, this resulted for larger grain size in the prepared ferrite samples.

The values of lattice parameters were obtained for all the samples using XRD data and are listed in Table 1. The variation of lattice parameter with $\mathrm{Cu}$ content is shown in Figure 2. From Figure 2, it is observed that the lattice parameter increases with increasing copper content $x$. This behavior of lattice parameter with $\mathrm{Cu}$ content $x$ is explained on the basis of difference in ionic radii of $\mathrm{Ni}^{2+}(0.69 \AA)$ and $\mathrm{Cu}^{2+}(0.724 \AA)$. Similar types of results were observed in the investigation of S. Manjura Hoque et al. [6] and M. A. Gabal et al. [7]. In the case of our samples, the lattice parameters were found to be slightly higher than those reported by others. The enhanced lattice parameters might be occurred due to solgel method. The X-ray density of all the $\mathrm{Ni}_{1-x} \mathrm{Cu}_{x} \mathrm{Fe}_{2} \mathrm{O}_{4}(0$ $\leq x \leq 1.0)$ ferrites has been calculated from the molecular weight and the volume of the unit cell using the relation,

$$
d_{x}=\frac{8 M}{N a^{3}}\left[\mathrm{~g} / \mathrm{cm}^{3}\right]
$$

where, $M$ is molecular weight, $N$ is Avogadro's number and $a$ is lattice parameter.
Table 1. Lattice parameter $(a)$, X-ray density $\left(d_{x}\right)$, saturation magnetization $\left(M_{S}\right)$ and magnetic moment $\left(\eta_{B}\right)$ with $\mathrm{Cu}$ content $x$.

\begin{tabular}{ccccc}
\hline $\boldsymbol{x}$ & $\boldsymbol{a}(\AA)$ & $\boldsymbol{d}_{\boldsymbol{x}}\left(\mathbf{g m} / \mathbf{c m}^{3}\right)$ & $\boldsymbol{M}_{\boldsymbol{S}}(\mathbf{e m u} / \mathbf{g})$ & $\boldsymbol{\eta}_{\boldsymbol{B}}\left(\boldsymbol{\mu}_{\boldsymbol{B}}\right)$ \\
\hline 0 & 8.281 & 4.92 & 35.8 & 1.508 \\
0.2 & 8.327 & 4.97 & 37.7 & 1.594 \\
0.4 & 8.352 & 4.97 & 44.1 & 1.870 \\
0.5 & 8.362 & 5.03 & 46.9 & 1.992 \\
0.7 & 8.380 & 4.78 & 41.9 & 1.786 \\
0.8 & 8.412 & 4.62 & 32.5 & 1.387 \\
0.9 & 8.444 & 4.79 & 26.9 & 1.150 \\
\hline
\end{tabular}

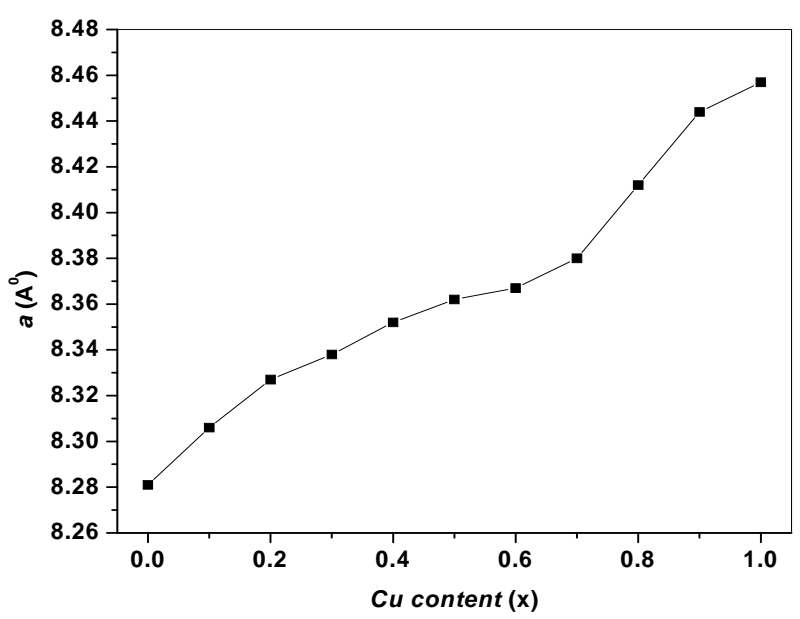

Figure 2. Variation of lattice parameter $a$ with $\mathrm{Cu}$ content $x$.

The variation of X-ray density with copper content is also shown in Table 1. The X-ray density is found to decrease with increasing $\mathrm{Cu}$ content $x$. The $\mathrm{X}$-ray density is found to depend on the lattice parameter and molecular weight of the samples.

Figure 3 shows the typical SEM microstructures of $\mathrm{Ni}_{1-x} \mathrm{Cu}_{x} \mathrm{Fe}_{2} \mathrm{O}_{4}(0 \leq x \leq 1.0)$ samples. From the microstructures one can clearly see the structural changes with the copper content $x$. The morphology and grain size of the samples seem to be non-uniform with somewhat agglomeration in the synthesized samples which is unavoidable. In few samples with $x=0.2$ and 0.5 , one can see that the grains are well separated. From the preliminary observations of the SEM images, we could say that the grain size is slightly affected by the $\mathrm{Cu}$ doping concentration.

Magnetization measurements of $\mathrm{Ni}_{1-x} \mathrm{Cu}_{x} \mathrm{Fe}_{2} \mathrm{O}_{4}(0 \leq x$ $\leq 1.0)$ samples were carried out using a vibrating sample magnetometer (VSM) with the maximum applied field of $8 \mathrm{kOe}$ at room temperature. The hysteresis loops were found to be well saturated with the available applied field. The obtained hysteresis loops are shown in Figure 4. The hysteresis loops display the characteristics of soft-magnetic materials. The saturation magnetization $\left(M_{S}\right)$ was 


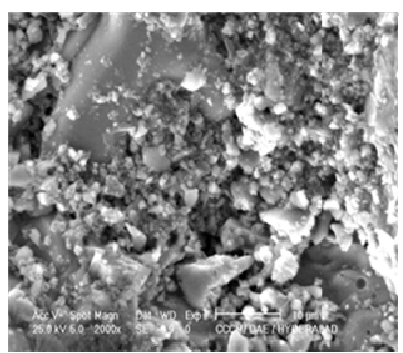

$x=0.0$

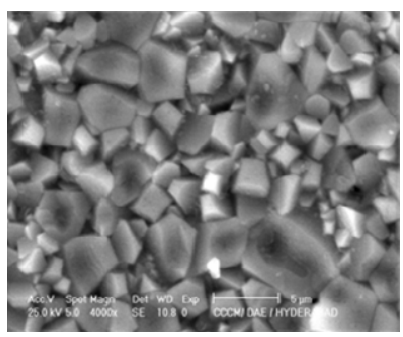

$x=0.5$

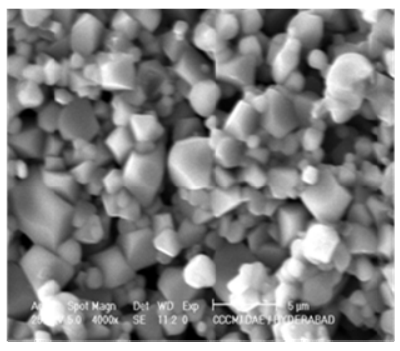

$x=0.9$

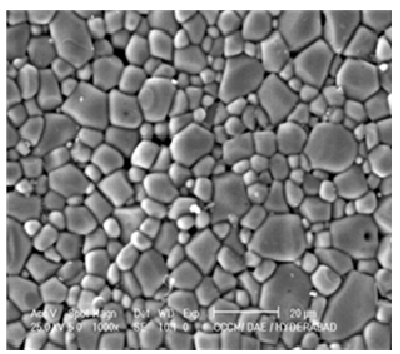

$x=0.2$

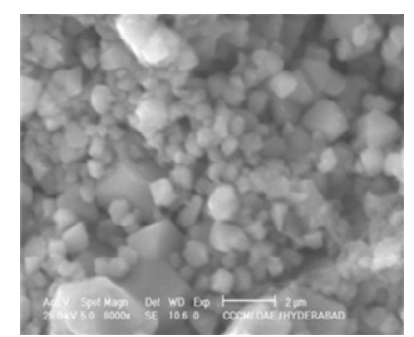

$x=0.7$

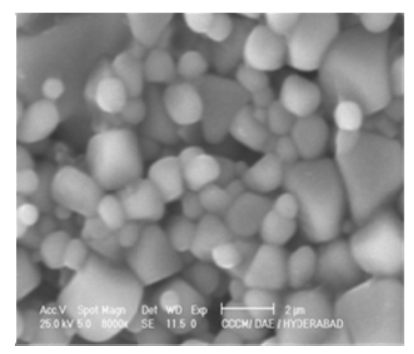

$x=1.0$

Figure 3. SEM images of $\mathrm{Ni}_{1-x} \mathrm{Cu}_{x} \mathrm{Fe}_{2} \mathrm{O}_{4}(0 \leq x \leq 1.0)$ ferrites.

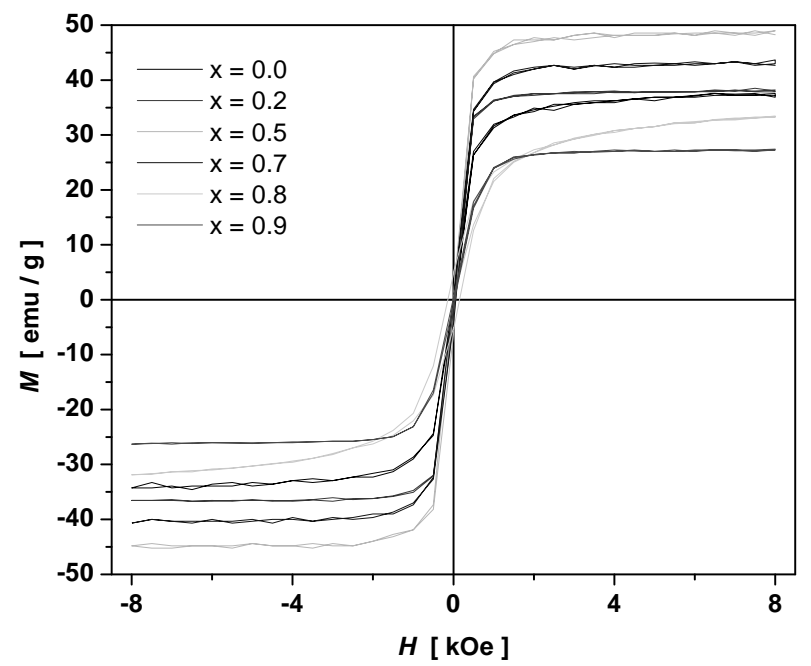

Figure 4. Hysteresis loops of $\mathrm{Ni}_{1-x} \mathrm{Cu}_{x} \mathrm{Fe}_{2} \mathrm{O}_{4}(0 \leq x \leq 1.0)$ ferrites.

found to increase up to $x=0.5$ and then gradually decrease with further increase of $\mathrm{Cu}$ content $x$ as shown in Figure 5. The experimental magnetic moment $\left(\eta_{B}\right)$ is determined from the saturation magnetization data using the following relation [7]:

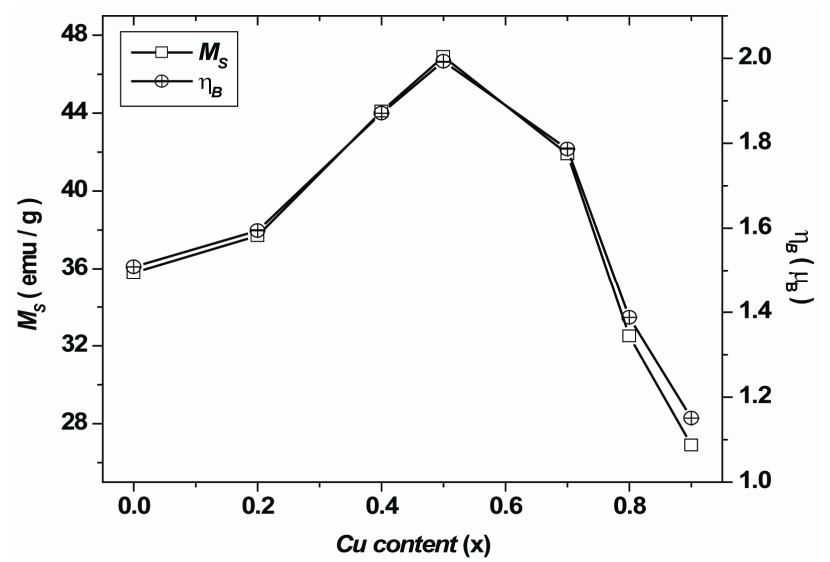

Figure 5. Variation of saturation magnetization and magnetic moment with $C u$ content $x$.

$$
\eta_{B}=\frac{M_{W} \times M_{S}}{5585}
$$

where, $M_{W}$ is the molecular weight of the sample and $M_{S}$ is the saturation magnetization in $\mathrm{emu} / \mathrm{g}$.

The calculated values of the experimental magnetic moment $\left(\eta_{B}\right)$ and the saturation magnetization are shown in Table 1. The trend in the variation with $\mathrm{Cu}$ content $x$ in both the cases is found to be similar. The variation of magnetization with $\mathrm{Cu}$ content $x$ is very well in agreement with the one reported by Doh et al. [8] on $\mathrm{Ni} \mathrm{Cu}$ ferrite prepared by coprecipitation method. Gabal et al. [9] have observed a decrease in magnetization with an increase in $\mathrm{Cu}$ content $x$. It is observed that the preparation technique plays an important role in modifying the magnetic properties of spinel ferrites.

From Figure 5, it is clear that the samples with $x=0.0$ to 1.0 show ferrimagnetic behavior which increases initially from $x=0.0$ to 0.5 and decrease from $x=0.5$ to 0.9 suggesting a change in magnetic ordering [16]. The variation of $\eta_{B}$ with $\mathrm{Cu}^{2+}$ content $x$ can be explained on the basis of the fact that $\mathrm{Cu}^{2+}$ ions replace the magnetic $\mathrm{Fe}^{3+}$ ions at tetrahedral (A) site. Thus, magnetic moment of Bsite decreases with $\mathrm{Cu}$ content $x$. Hence, it can be understood that $\mathrm{Cu}$ ions replace $\mathrm{A}$-site $\mathrm{Fe}$ ions and as a result, A-site moment decreases. However, difference between A-site moment and B-site moment increases. Thus the increase in magnetic moment $\eta_{B}$ with $\mathrm{Cu}$ content $x$ up to $x$ $=0.5$ is due to non-collinear ferrimagnetic structure. The decrease in $\eta_{B}$ for $x>0.5$ indicates the possibility of a Neel's collinear ferrimagnetic structure. Gabal et al. [9] suggested that the presence of $\mathrm{Cu}^{2+}$ in A site could influence the decrease in the magnetization by the substitution of $\mathrm{Ni}^{2+}$ by $\mathrm{Cu}^{2+}$.

The observed variations in the magnetization could be explained on the basis of cation distribution and exchange interaction between iron and copper ions at tetrahedral $\mathrm{A}$ and octahedral $\mathrm{B}$ sites. When $\mathrm{Cu}^{2+}$ ions are introduced 
at the expense of nickel ions, some of the $\mathrm{Fe}^{3+}$ ions migrate from $\mathrm{A}$ to the $\mathrm{B}$ sites in view of the site preferences for different ions. This increases the $\mathrm{Fe}^{3+}$ ion concentration at B-sites. As a result, the magnetic moment of $\mathrm{B}$ sub-lattice increases. However, as $\mathrm{Cu}^{2+}$ concentration increases, the iron ions left at A-site, being small in number, the A-B interaction experienced by B-site iron ions decreases. Also, the increased number of $\mathrm{Fe}^{3+}$ ions at the $\mathrm{B}$-site increases the B-B interaction, resulting in spin canting [17]. Consequently, the magnetization of B sub-lattice is decreased. The increase in the $\mathrm{Cu}$ content in the sample, therefore, decreases the magnetic moment of the A sub-lattice. The reason for decrease in magnetization may also be due to the fact that low $\mathrm{Cu}^{2+}$ concentration reduces the number of spins occupying the A sublattices, causing the net magnetization to increase. As the $\mathrm{Cu}^{2+}$ content increases, the exchange interactions are weakened and the B spins are no longer held rigidly parallel to the few remaining A spins. The decrease in the B sub-lattice moment, interpreted as a spin departure from co-linearity, causes the effect known as canting. Magnetization values of presently prepared samples are comparatively smaller than those of oxalate prepared samples [9]. Smaller magnetization, in the presently prepared samples, compared to the other synthesis methods is expected due to the surface disorder and probable modified cationic distribution [18].

\section{Conclusion}

The Ni-Cu Ferrites were successfully prepared by sol-gel method and they are sintered at $1000^{\circ} \mathrm{C}$ for 24 hours. The sintering temperature and sintering time plays vital role in determining the particle size. The X-ray diffraction studies clearly showed the formation of single phase spinel structure and the particle size beyond the nanoscale. The lattice parameter is found to increase with increasing copper content. The copper substitution was found to have a significant effect on both the structural and magnetic properties. The saturation magnetization results exhibit a non-collinear ferrimagnetic structure for $x=0.0$ to 0.5 and Neel's collinear ferrimagnetic structure for $x=0.5$ to 0.9 suggesting a change in magnetic ordering.

\section{Acknowledgements}

The authors express their sincere thanks to Prof. P. Kistaiah, Head and Chairman Board of Studies, Department of Physics, Osmania University, Hyderabad. The author, KVK, expresses his gratitude to Dr. B. Sudheer Prem Kumar, Principal (I/c), JNTUH College of Engineering, Nachupally (Kondagattu), Karimnagar-Dist., A.P., India for his encouragement.

\section{REFERENCES}

[1] C. Venkataraju, G. Sathishkumar and K. Sivakumar, "Effect of Cation Distribution on the Structural and Magnetic Properties of Nickel Substituted Nanosized Mn-Zn Ferrites Prepared by Co-Precipitation Method," Journal of Magnetism and Magnetic Materials, Vol. 322, No. 2, 2010, pp. 230-233. doi:10.1016/j.jmmm.2009.08.043

[2] A. Goldman, "Modern Ferrite Technology," Van Nostrand Reinhold, New York, 1990.

[3] S. E. Shirsath, B. G. Toksha and K. M. Jadhav, "Structural and Magnetic Properties of $\mathrm{In}^{3+}$ Substituted $\mathrm{NiFe}_{2} \mathrm{O}_{4}$," Materials Chemistry and Physics, Vol. 117, No. 1, 2009, pp. 163-168. doi:10.1016/i.matchemphys.2009.05.027

[4] C. Upadhyay, H. C. Devabrata Mishtra, S. Verma and R. P. Anand Das, "Effect of Preparation Conditions on Formation of Nanophase Ni-Zn Ferrites through Hydrothermal Technique," Journal of Magnetism and Magnetic Materials, Vol. 260, No. 1-2, 2003, pp. 188-194. doi:10.1016/S0304-8853(02)01320-3

[5] Z. Cvejic, S. Rakic, A. Kremenovic, B. Antic, C. Jovalekic and P. Colomban, "Nanosize Ferrites Obtained by Ball Milling: Crystal Structure, Cation Distribution, SizeStrain Analysis and Raman Investigations," Solid State Sciences, Vol. 8, No. 8, 2006, pp. 908-915. doi:10.1016/j.solidstatesciences.2006.02.041

[6] S. Manjura Hoque, Md. Amanullah Choudhury and Md. Fakhrul Islam, "Characterization of Ni-Cu Mixed Spinel Ferrite," Journal of Magnetism and Magnetic Materials, Vol. 251, No. 3, 2002, pp. 292-303. doi:10.1016/S0304-8853(02)00700-X

[7] M. A. Gabal, Y. M. Al Angari and S. S. Al-Juaid, "A Study on $\mathrm{Cu}$ Substituted Ni-Cu-Zn Ferrites Synthesized Using Egg-White," Journal of Alloys and Compounds, Vol. 492, No. 1-2, 2010, pp. 411-415.

doi:10.1016/j.jallcom.2009.11.124

[8] G. Doh, E. B. Kim, B. H. Lee and J. H. Oh, "Characteristics and Synthesis of $\mathrm{Cu}-\mathrm{Ni}$ Ferrite Nanopowders by Coprecipitation Method with Ultrasound Irradiation," Journal of Magnetism and Magnetic Materials, Vol. 272-276, Part 3, 2004, pp. 2238-2240. doi:10.1016/j.jmmm.2003.12.926

[9] M. A. Gabal, Y. M. Al Angari and M. W. Kadi, "Structural and Magnetic Properties of Nanocrystalline $\mathrm{Ni}_{1-x} \mathrm{Cu}_{x} \mathrm{Fe}_{2} \mathrm{O}_{4}$ Prepared through Oxalates Precursors," Polyhedron, Vol. 30, No. 6, 2011, pp. 1185-1190. doi:10.1016/i.poly.2011.01.032

[10] J. Msomi and T. Moyo, "Effect of Domain Transformation on the Magnetic Properties of $\mathrm{Cu}_{x} \mathrm{Ni}_{1-x} \mathrm{Fe}_{2} \mathrm{O}_{4}$ Ferrites," Journal of Magnetism and Magnetic Materials, Vol. 321, No. 9, 2009, pp 1246-1250. doi:10.1016/j.jmmm.2008.11.003

[11] J. Azadmanjiri, H. K. Salehani, M. R. Barati and F. Farzan, "Preparation and Electromagnetic Properties of $\mathrm{Ni}_{1-x} \mathrm{Cu}_{x} \mathrm{Fe}_{2} \mathrm{O}_{4}$ Nanoparticle Ferrites by Sol-Gel AutoCombustion Method," Materials Letters, Vol. 61, No. 1, 2007, pp. 84-87. doi:10.1016/j.matlet.2006.04.011

[12] K. Roumaih, "The Transport Properties of the Mixed Ni$\mathrm{Cu}$ Ferrite," Journal of Alloys and Compounds, Vol. 465, 
No. 1-2, 2008, pp. 291-295. doi:10.1016/j.jallcom.2007.10.073

[13] X. Y. Tan, G. Y. Li, Y. Zhao and C. W. Hu, "The Effect of $\mathrm{Cu}$ Content on the Structure of $\mathrm{Ni}_{1-x} \mathrm{Cu}_{x} \mathrm{Fe}_{2} \mathrm{O}_{4}$ Spinels," Materials Research Bulletin, Vol. 44, No. 12, 2009, pp. 21602168. doi:10.1016/j.materresbull.2009.08.018

[14] D. R. Patil and B. K. Chougule, "Effect of Copper Substitution on Electrical and Magnetic Properties of $\mathrm{NiFe}_{2} \mathrm{O}_{4}$ Ferrite," Materials Chemistry and Physics, Vol. 117, No. 1, 2009, pp. 35-40.

doi:10.1016/j.matchemphys.2008.12.034

[15] A. T. Raghavender, N. Biliškov and Ž. Skoko, "XRD and IR Analysis of Nanocrystalline Ni-Zn Ferrite Synthesized by the Sol-Gel Method," Materials Letters, Vol. 65, No. 4, 2011, pp. 677-680. doi:10.1016/j.matlet.2010.11.071
[16] R. G. Kulkarni and H. H. Joshi, "Comparison of Magnetic Properties of $\mathrm{MgFe}_{2} \mathrm{O}_{4}$ Prepared by Wet-Chemical and Ceramic Methods," Journal of Solid State Chemistry, Vol. 64, No. 2, 1986, pp. 141-147. doi:10.1016/0022-4596(86)90133-7

[17] S. E. Shirsath, B. G. Toksha, R. H. Kadam, S. M. Patange, D. R. Mane, G. S. Jangam and A. Ghasemi, "Doping Effect of $\mathrm{Mn}^{2+}$ on the Magnetic Behavior in Ni-Zn Ferrite Nanoparticles Prepared by Sol-Gel Auto-Combustion," Journal of Physics and Chemistry of Solids, Vol. 71, No. 12, 2010, pp. 1669-1675. doi:10.1016/j.jpcs.2010.08.016

[18] B. Parvatheeswara Rao, O. Caltun, W. S. Cho, C.-O. Kim and C. Kim, "Synthesis and Characterization of Mixed Ferrite Nanoparticles," Journal of Magnetism and Magnetic Materials, Vol. 310, No. 2, 2007, pp. e812-e814. doi:10.1016/j.jmmm.2006.10.771 